\title{
Developing a Taxonomy for Visual Representation Characteristics of Submicroscopic Particles in Chemistry Textbooks
}

\author{
George Papageorgiou 1*, Vasilios Amariotakis', Vasiliki Spiliotopoulou²
}

${ }^{1}$ Department of Primary Education, Democritus University of Thrace, Alexandroupolis, Greece, ${ }^{2}$ Department of Education, School of Pedagogical and Technological Education (ASPETE) - Branch of Patras, Greece

*Corresponding Author: gpapageo@eled.duth.gr

\section{ABSTRACT}

The illustration characteristics of 221 visual representations (VRs) of submicroscopic particles in nine Greek secondary chemistry school textbooks from the last three decades were analyzed. This analysis was done to develop a taxonomy that could help science teachers and curricula designers evaluate the efficacy of such characteristics on student learning. The sample was quantitatively divided into three distinct time periods and analyzed qualitatively using the phenomenographic method through an inductive approach. The "unit of analysis" was every VR of submicroscopic particles together with its caption. Qualitative analysis revealed characteristics such as the type of VR, the way of expression, the signs used, the dimensions represented, the text included, and the complexity of the VR. Quantitative analysis revealed the effect of time on the characteristics. The taxonomy provides an integrated view of VRs illustration characteristics that could help in realizing the multiple ways in which the meaning of a VR could be interpreted, whereas it can also contribute to future appropriate design and use of such VRs toward a better science curriculum.

KEY WORDS: illustration characteristics; visual representations, phenomenographic analysis; chemistry textbooks; taxonomy

\section{INTRODUCTION}

○

lextbooks are one of the most important instructional tools, playing a major role in the teaching and learning procedure (e.g., Kuhn, 1970; Stinner, 1992; Yore et al., 1998). School science textbooks are used by many teachers as the primary organizer of the subject matter, having an impact on the design of lessons, the assignment of activities and the construction of tests (Glynn and Muth, 1994). As prominent components of curricula at all levels of education, they are often associated with reform recommendations and significantly contribute to the curricula development and evolution (Abd-ElKhalick et al., 2008; Chiappetta and Fillman, 2007).

Due to their importance, school textbooks analysis is critical for science education, as it could provide us with valuable information for the construction of students' knowledge and the whole teaching and learning process (Souza and Porto, 2012). In a school textbook, various modalities, such as texts (verbal mode) and visual representations (VRs) (visual mode), are used to help students to acquire scientific knowledge. Their appropriateness and expression accuracy are determinant factors for the students' understanding of the relevant concepts or phenomena (e.g., Boo, 1998; Onwu and Randall, 2006; Sanger and Greenbowe, 1997). Although both texts and VRs are valuable tools, some researchers (e.g., Kress et al., 2001) suggest that VRs are regarded as more than meaning maker tools, since they can express ideas which are not easy to be expressed in the verbal mode. As such, they have become an increasing larger interest area for analyses (e.g., Abd-ElKhalick et al., 2008).

VRs are, in fact, external representations, which lead students to construct corresponding internal representations (e.g., Eliam and Poyas, 2010; Gilbert, 2008, 2010; Schnotz, 2002). This means that any deficiency in their characteristics as illustrations can cause problems in their interpretation by the students or even the teachers, leading them to relevant misconceptions (Billings and Klanderman, 2000; Onwu and Randall, 2006). Such characteristics could be symbols, signs, ways of expressions, complexity, graphical technics, etc., and we will refer to them using the term illustration characteristics. These are much more important, especially in cases, where VRs represent abstract concepts that are not visible in the real world, determining decisively the configuration of the corresponding students' internal representations.

Focusing on the field of chemistry, the VRs of molecules, atoms, ions, or subatomic particles are of paramount importance, since student understanding of such VRs is a precondition for the understanding of the real-world phenomena - we will refer to them using the term VRs of submicroscopic particles. The 
illustration characteristics of these VRs are in the central objective of the present study.

\section{THEORETICAL BACKGROUND}

In studies relevant to the analysis of science textbooks, VRs are often present, since they play an important role in the understanding of science concepts and phenomena (e.g., Abd-El-Khalick et al., 2008; Cheng et al., 2015; Noh and Scharmann, 1997; Shehab and BouJaoude, 2017; Wu and Shah, 2004). Their presence has increased over the past few decades, possibly due to the development of the modern graphical technologies that facilitate the use of any visual mode to present more effective various scientific ideas.

The perspective and the focus of such textbooks' analyses vary significantly according to the main objectives of the studies. Devetak and Vogrinc (2013), for instance, analyzed science textbooks in three levels, namely, the "general structure," the "textual material," and the "visual material." Devetak and Vogrinc (2013) categorized images as "realistic" ones that present reality according to the human optical perception (photograph and drawing), as "conventional" images designed according to a technoscientific consensus in the most concise way (graphs, diagrams, maps, and molecular structures) and as "hybrid" images that combine the realistic and the conventional ones. Similar is the classification of Dimopoulos et al. (2003), who analyzed exclusively images of Greek science textbooks.

In cases where the classification of the VRs of science textbooks is the issue, the majority of the studies follow a similar logic, categorizing their type mostly as photographs, drawings, graphs, diagrams, maps, and/or equations (e.g., Roth et al., 1999; Slough et al., 2010; Tsui and Treagust, 2013). However, a number of studies present a more specific analysis of one or more of these types of VRs. Thus, when Roth et al. (1999) further analyzed graphs' type, they identified a number of sub-categories such as "scatter plots with line connecting points," "scatter plots with best-fit curve," "scatter plot with plot of mathematical model," "graph mathematical model," or "graphical model without scales of units." Apart from the type of a VR, also its function appears to be among the main objectives of a textbooks' analysis. Pozzer-Ardenghi and Roth (2003), for instance, analyzed photographs of science textbooks, identified four categories related to their function, namely, "decorative," "illustrative," "explanatory," and "complementary." Through this analysis and other similar ones (e.g., Spiliotopoulou-Papantoniou et al., 2009; Slough et al., 2010), the role of the caption (e.g., there is not any caption in a decorative VR) and the significance of the connection of a VR to the main text were also revealed.

Focusing on VRs depicted in chemistry textbooks or in chemistry-related chapters of general science textbooks, one can see that a significant number of them refer to submicroscopic particles such as molecules, atoms, ions, or subatomic particles (e.g., Gkitzia et al., 2011; Han and Roth, 2006; Nyachwaya and Wood, 2014; Shehab and BouJaoude, 2017). In the relevant textbooks' analyses, researchers generally follow the categorization logic reported above concerning the type or the function of the VRs. However, submicroscopic particles are unseen, and relevant VRs present many particularities since it is very difficult to find a satisfying way to depict what really holds true in that small world. Thus, the illustration characteristics of the VRs concerning submicroscopic particles appear to be very important, and therefore, they offer a very interesting objective for the researchers. For instance, Han and Roth (2006) analyzed the structure and the function of the VRs representing such submicro-entities (along with macro-entities) in Korean science textbooks. Although they generally used the categorizations presented above, the whole analysis took place in a semiotic context. As a result, through this analysis, a number of specific characteristics of the VRs (illustration characteristics) were also revealed, such as the symbols/signs used for the depiction of particles (circles, molecular models or person-like shapes) or for the depiction of movements (line, circular or shadow tails). Furthermore, in another context related to evaluation criteria for VRs, Gkitzia et al. (2011) analyzed a number of VRs included in Greek school chemistry textbooks, some of which referred to submicroscopic particles. Among these criteria, a number of illustration characteristics (symbols/signs categorized as "surface characteristics," such as circles, lines, and symbols such as,$+ \mathrm{e}^{-}$) was also examined in relation to how explicit and understandable for the students are. Resulting categories were "explicit," "implicit," and "ambiguous."

Searching the relevant literature, a number of such analyses of VRs concerning submicroscopic particles in various contexts and criteria could be found (e.g., Rodriguez and Niaz, 2004; Niaz and Coştu, 2009; Nyachwaya and Gillaspie, 2016; Nyachwaya and Wood, 2014). However, it seems that none of them are based on a systematic analysis scheme that was constructed especially for VRs of submicroscopic particles targeting to their illustration characteristics. Taking into account the importance of these characteristics for the understanding of the VRs of submicroscopic particles, the development of such an analysis appears to be an interesting challenge.

\section{RATIONALE OF THE STUDY}

In the context described above, the central idea was to develop a systematic analysis exclusively of the VRs of submicroscopic particles, to reveal any of their characteristics that can affect students' relevant understanding. For this purpose, the VRs of submicroscopic particles depicted in Greek chemistry school textbooks, which have been used during the past three decades in secondary education, were analyzed. From this effort, a systemic network emerged, having four axes of concern: First, the VRs' main conceptual framework, second their illustration characteristics, third their didactic characteristics, and fourth their relations to the main text. The results from the analysis of the first axis (VRs' main conceptual framework) have been already presented (Papageorgiou et al., 2017), whereas the 
present paper refers to the analysis of the second axis, which is, in fact, a taxonomic classification system for the VRs' illustration characteristics. Thus, the main objective of the present paper concerns the development of such a taxonomic system in a cohesive way, to help science teachers and curricula designers to realize the pluralism of these characteristics and their relations between and within resulting categories. In particular, the following research questions were addressed:

- How could the illustration characteristics of the VRs of submicroscopic particles, included in the Greek secondary chemistry textbooks, form a taxonomic system in a cohesive way?

- To what extent did the categories of such a system differentiate across 3 times periods of Greek secondary education?

\section{METHOD}

\section{The Sample}

The sample comprises a total number of 221 VRs of submicroscopic particles depicted in nine chemistry textbooks that have been used over the past three decades in Greek secondary education. The textbooks were written for the $8^{\text {th }}, 9^{\text {th }}$, and $10^{\text {th }}$ grades during the three periods: 1990-1996, 1997-1998, and 2007-2011 (Appendix). Eighty-two of the VRs were depicted in the three textbooks of the $1^{\text {st }}$ period, 37 VRs were depicted in the $2^{\text {nd }}$ period, and 102 were depicted in the $3^{\text {rd }}$ period.

\section{The Unit of Analysis}

The "unit of analysis" was every VR of submicroscopic particles together with its caption. However, any information of the main text that could clarify the illustration characteristics of the unit was also taken into account. As a "VR of submicroscopic particles" was considered to be any visual object representing entities of either, the submicro- or the macro-level. Specifically, (a) atoms, molecules, ions or subatomic particles, depicted using various scientific conventions, such as structural formulas, ball-and-stick models or appropriate symbols/signs, and (b) macroscopic objects, which analogically or metaphorically refer to corresponding submicroscopic entities or relevant events.

\section{The Procedure}

The VRs of the sample were analyzed according to the phenomenographic method (Albertazzi, 2013; Marton, 1986; Marton and Booth, 1997). By the implementation of such a method, an exploration of the qualitatively different ways in which one can experience and understand a situation was evaluated. A core premise of phenomenography is the assumption that different ways of experiencing the situation are logically related to one another, typically by way of hierarchically inclusive relationships (Marton and Booth, 1997). Consequently, the researcher aims to constitute not just a set of different meanings, but a logically inclusive structure relating the different meanings. Thus, the categories of description constituted by the researcher to represent the different ways of experiencing the situation are seen as representing a structured set (Åkerlind, 2005). This, despite the possibly existed variation, provides a way of looking at the collective human experience of a situation holistically. In the present study, the "situation" concerns the submicroscopic particles and the "experience" its VRs in the chemistry textbooks, whereas the "one who experiences" is any of the researchers.

In this context, the content of every unit was qualitatively analyzed (Mayring, 2000) to form the corresponding categories through an inductive approach. During the study, a systemic network emerged (Bliss et al., 1983) comprised the four-axis as reported above, one of which concerns the "illustration characteristics" of the VRs that are presented in this paper. For the formation of the final categories of this taxonomic system (i.e., this particular axis of the whole systemic network), three researchers worked independently through the inductive approach, step by step, for the total of the sample. In each step, each one of the researchers was trying to categorize a number of VRs in the already existing categories. When this was not possible, new categories were formed, or existing categories were modified. At the end of each step, the three researchers compared their categorizations to each other, and any disagreement was discussed in a meeting until a total agreement has been reached. This was repeated gradually for the entire sample.

When the qualitative content analysis was accomplished, descriptive statistic tools were applied for a basic quantitative analysis of the sample in relation to the three periods of the textbooks.

\section{RESULTS AND DISCUSSION}

\section{The Resulting Taxonomy - Descriptions and Definitions}

Following the procedure described above, the analysis of the VRs led to the development of the taxonomy presented in Figure 1, concerning their illustration characteristics. One can read this system from the left to the right, starting from the "illustration characteristics" and following any possible path, through a curly bracket or a square bracket, to the final categories. A curly bracket means that the VRs of a general category (on the left) could be categorized to one or more elementary categories (on the right). On the contrary, a square bracket means that the VRs of a general category (on the left) are categorized exclusively to one of the elementary categories (on the right).

As Figure 1 shows, the illustration characteristics of the VRs of the sample could be categorized in any of the categories: Type, way of expression, sign used, dimensions, text included, and complexity. In the category type, the VRs of the sample are categorized according to their degree of abstractness (Pozzer-Ardenghi and Roth, 2003), something that is related to the use or not of particular symbols as well as to the depiction or not of details relevant to the main concepts that the VR conveys. On this basis, a VR could be a photograph, when it 


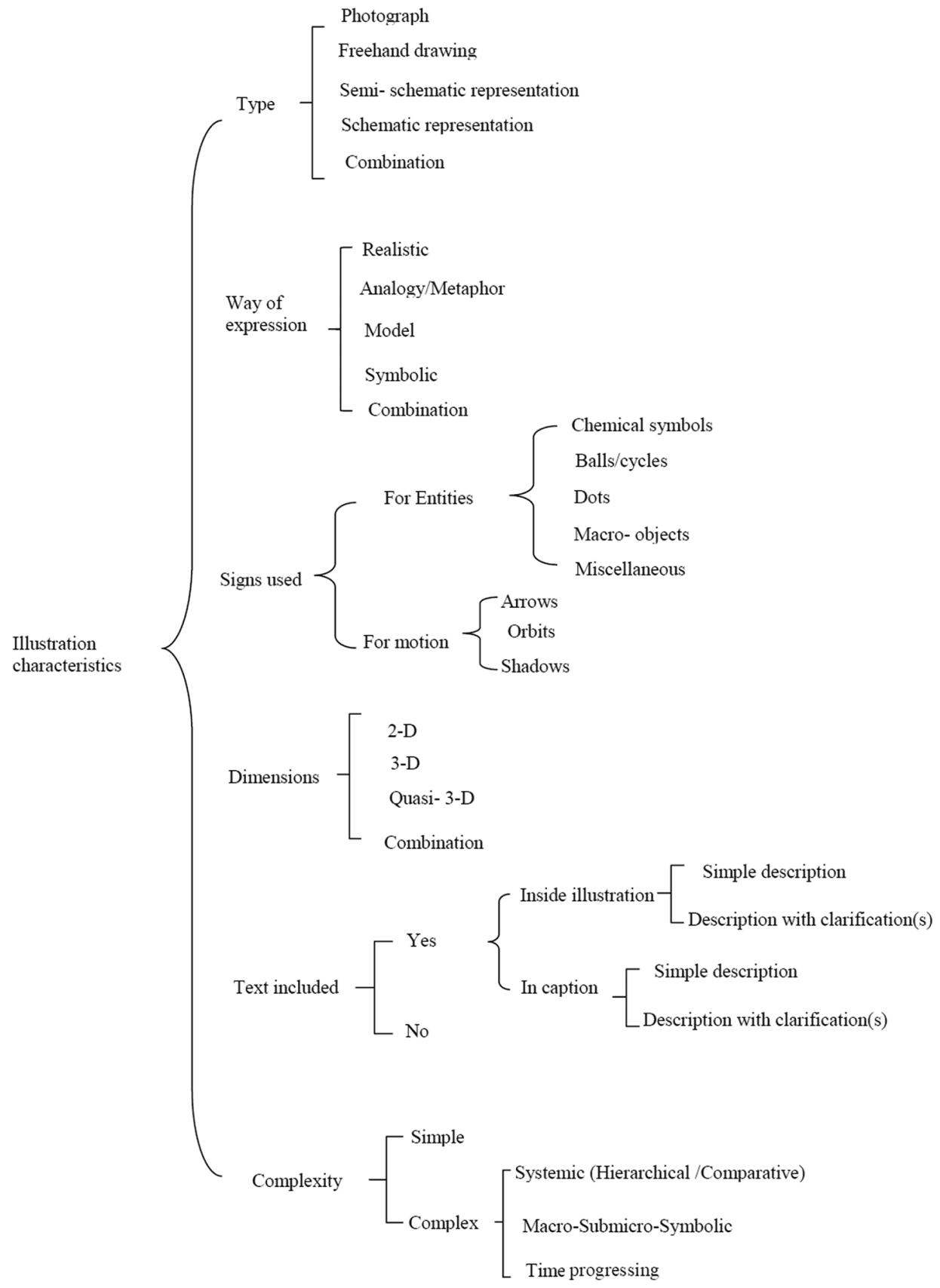

Figure 1: The taxonomy concerning the "illustration characteristics" of visual representations

depicts something as it can be seen in reality, for example, a photo of a ball-and-stick model made of plastic, independently of the mean that was used for its production (analogical camera, digital camera or other electronic device).

A VR could also be a freehand drawing, when it attributes an entity or/and an event in a quite realistic way, although some of the total information could be omitted or some symbols could be used. For instance, in Figure 2, some dots represent molecules of a liquid that one can smell.

In this category, draft drawings (sketches) are also included. The freehand drawings could be designed through a conventional or an electronic mean and they could be black/white or colored.
On the contrary, when the degree of abstraction increases, entities or events are depicted in a diagrammatical way by omitting details that are considered as "noise" and using scientific conventions (e.g., balls/cycles for the representation of particles and curved lines for the representation of orbits), then a VR is categorized as a schematic representation (e.g., Figure 3).

However, there were cases where the use of a number of colors and graphical technics ascribe to VRs a more realistic aspect. These cases are separately categorized as semi-schematic representations (e.g., Figure 4).

In addition, there were VRs that combined illustration characteristics of some of the above categories. These 


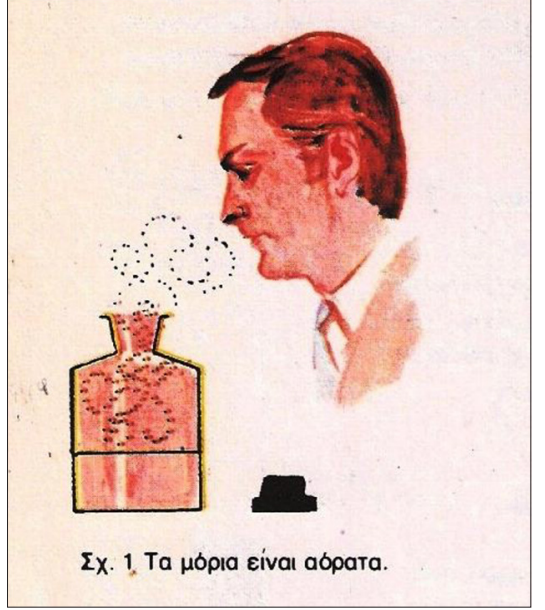

Figure 2: An example of a freehand drawing. Some dots represent molecules of a liquid that one can smell. The figure was taken from the textbook of Frassari and Drouka-Liapati (1993).

fall into the category combination. For instance, Figure 5 combines characteristics of the categories photograph and semi-schematic.

In the category way of expression (Figure 1), the VRs of submicroscopic particles were further categorized according to the means/ways through which they expressed the submicroscopic particles. Thus, although it seems difficult to find a realistic way expressing submicroscopic particles, VRs created by the use of scanning tunneling microscopy (STM) could be considered as such.

Among other ways expressing submicroscopic particles or events involving submicroscopic particles is that of an analogy or a metaphor. For instance, the VR of Figure 6 expresses the way in which an enzyme acts through the analogy "lock and key." A model could also be a way to express submicroscopic entities or events. For instance, a photo of a plastic balland-stick model, which is a photograph as type, falls into the category model as a way of expression. A further way of expression is symbolic. Although a VR comprising exclusively symbols is not considered as a VR of submicroscopic particles (and thus, it is not included in the sample of the present study), there are cases, where symbols express an "iconic value," such as Lewis structures or structural formulae. According to Talanquer (2011), these cases represent, in fact, submicroscopic entities in a symbolic way, and thus, such VRs of the sample were categorized as symbolic.

Other VRs that combine two or more of the above ways of expression are categorized as a combination. For instance, the VR of Figure 4, which was categorized according to its type as semi-schematic, expresses particles of $\mathrm{Na}^{+}$and $\mathrm{Cl}^{-}$in a lattice of $\mathrm{NaCl}$ through a model (corresponding balls) and relevant symbols clarifying the depicted submicroscopic entities. Furthermore, the VR of Figure 2, which was categorized according to its type as freehand drawing, falls into this category, since it combines realistic aspects with a model (dots) to express the smell of ether evaporating from a bottle.

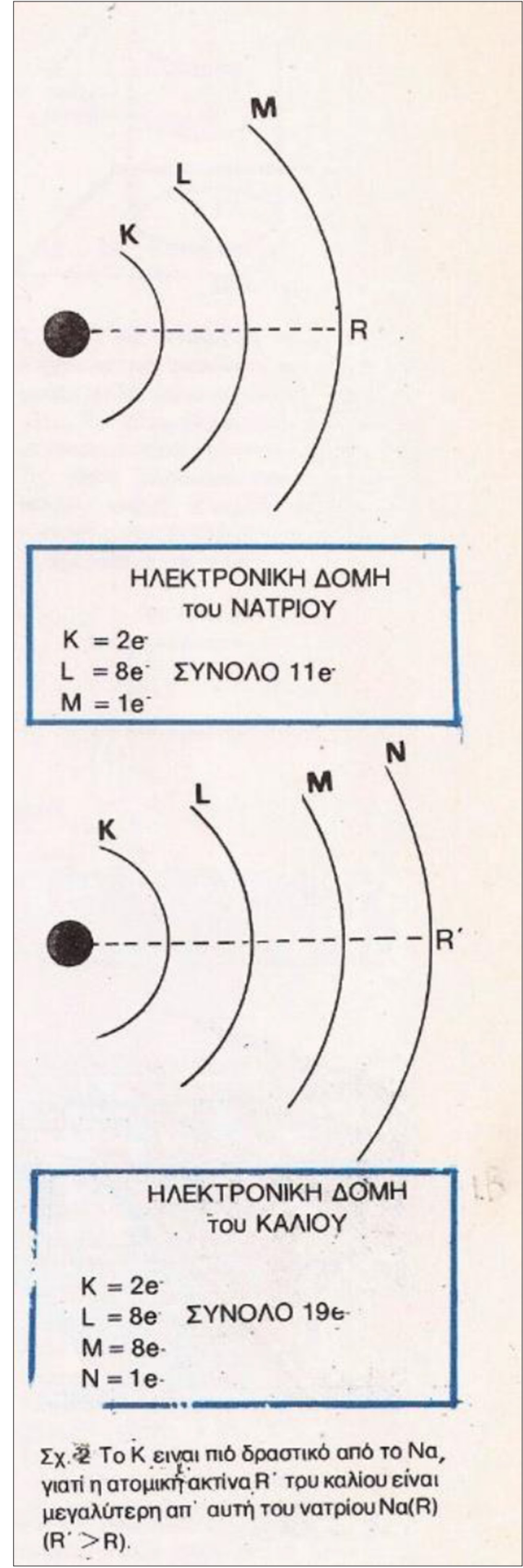

Figure 3: An example of schematic representation. Figure 3 depicts the electronic configuration of both sodium $(\mathrm{Na})$ and potassium $(\mathrm{K})$, showing that the atomic radius of $\mathrm{K}$ is bigger than that of $\mathrm{Na}$. The figure was taken from the textbook of Frassari and Drouka-Liapati (1993) 
As many researchers have suggested (e.g., Han and Roth, 2006; Kozma and Russell, 1997), the signs that are used to represent entities or events play a determinative role in their understanding. In the above categories and especially when

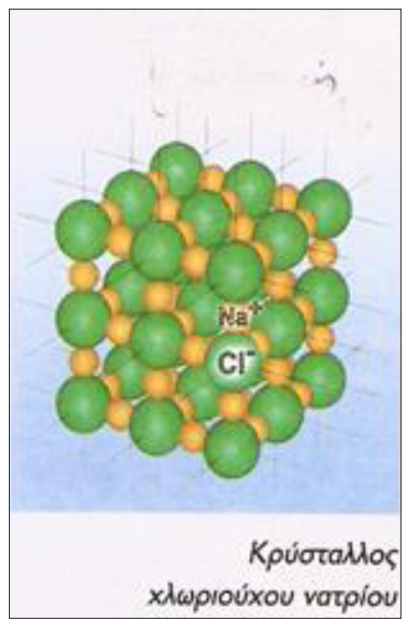

Figure 4: An example of a semi-schematic representation. It represents a lattice of sodium chloride $(\mathrm{NaCl})$, where ions of sodium $\left(\mathrm{Na}^{+}\right)$and chlorine $\left(\mathrm{Cl}^{-}\right)$are depicted. The figure was taken from the textbook of Avramiotis et al. (2007) submicroscopic particles or relevant events are expressed through models, symbols, or their combination, particular signs are used for this purpose. These could be chemical symbols, balls (in three-dimensional (3-D) representations), and cycles (in two-dimensional (2-D) representations) or/ and dots, when the VRs concern submicroscopic particles. In some cases, these entities could be represented through a macroscopic object (such as a photo of a plastic ball-and-stick model) or other miscellaneous signs, such as squares and oval schemes. In cases of VRs depicting motion, arrows, orbits or/ and shadows are used. For instance, in Figure 7, the motion of electrons in the atom and the ion of lithium is represented by orbits.

The dimensions of a VR play also an important role when trying to understand the represented entities (e. g., Barta \& Stille, 1994; Wu et al., 2001). Thus, 3-D VRs provide the reader with a more realistic view of submicroscopic particles (e.g., Figure 4), whereas in 2-D VRs, the reader has to imagine how the third dimension is. However, in some VRs of the sample, although there is a sense of 3-D, the representation does not actually depict submicroscopic particles in 3-D. For instance, in Figure 8, although the use of balls represented ions and atoms as 3-D entities,

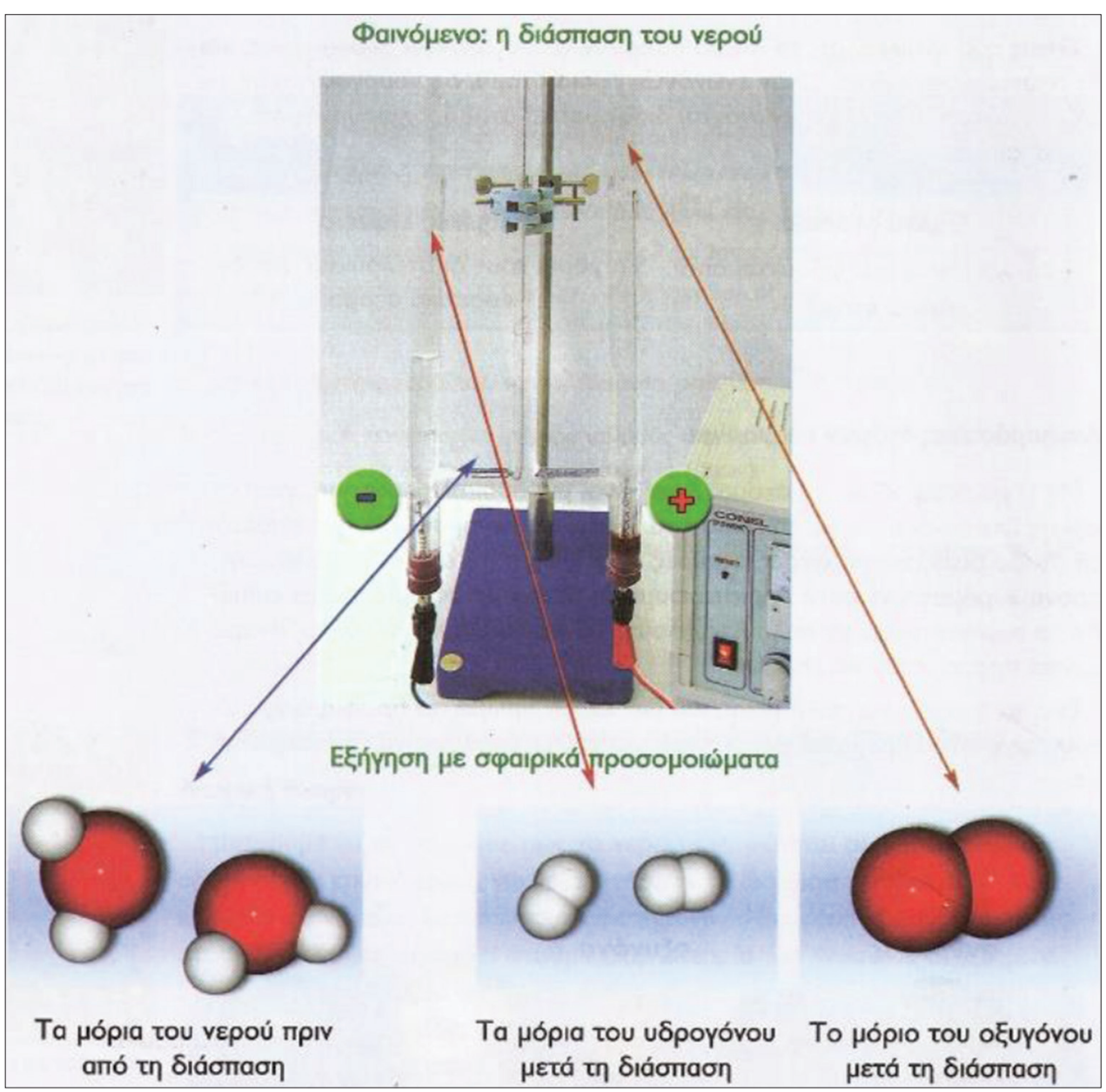

Figure 5: A combination of the categories photograph and semi-schematic. In Figure 5, an apparatus for electrolysis of water is depicted (photograph) along with molecules of water, hydrogen, and oxygen (semi-schematic). The figure was taken from the textbook of Avramiotis et al. (2007) 
the whole representation does not facilitate the relevant place and orientation of the ligands (molecules of water). These cases are characterized as quasi-3-D. In addition, a combination of 2-D and 3-D representations could also coexist in some VRs.

A text (few words or a whole sentence) could be also included in a VR. This could be in the caption of the VR or/and inside the illustration. In both cases, the text could simply describe what is depicted in the illustration (simple description) or it could provide the reader with more information, clarifications, or even explanations (description with clarification). For instance, Figure 9 falls into the category in caption $>$ description with clarification.

Since the understanding of a VR by students is related to the degree of its complexity especially by novices (e.g., Kozma and Russell, 1997; Patrick et al., 2005), among the illustration characteristics of the VRs of submicroscopic particles, their complexity was also studied. Thus, a VR is characterized

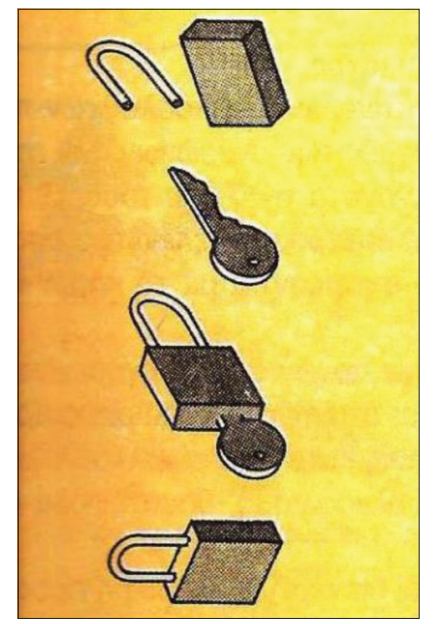

Figure 6: An example of an analogy. It expresses the way in which an enzyme acts through the analogy "lock and key." The figure was taken from the textbook of Georgiadou et al. (1998)

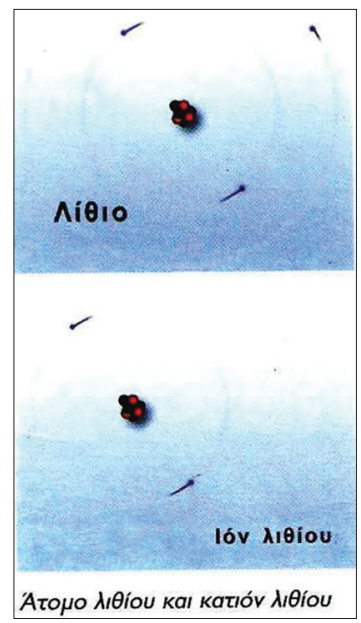

Figure 7: An example, where motion (in the atom and the ion of lithium) is represented by orbits. The figure was taken from the textbook of Avramiotis et al. (2007) as simple when it illustrates the depiction of just one situation (comprising entities or/and events). A complex VR illustrates two or more situations. For instance, the VR of Figure 4 is simple. In the category complex, a VR could fall into the category systemic (hierarchical/comparative) when submicroscopic particles are hierarchically classified according to their characteristics (e.g., their size) or/and they are compared to each other as for one or more characteristics (e.g., Figure 7). On the contrary, when a VR depicts aspect of a situation simultaneously at the two or all the three levels of representation, i.e. submicroscopic, macroscopic, and symbolic, then the VR falls into the category submicro-macrosymbolic (e.g., Figure 10). Finally, a VR is characterized as time progressing when it presents consecutive phases of an event (e.g., Figure 11).

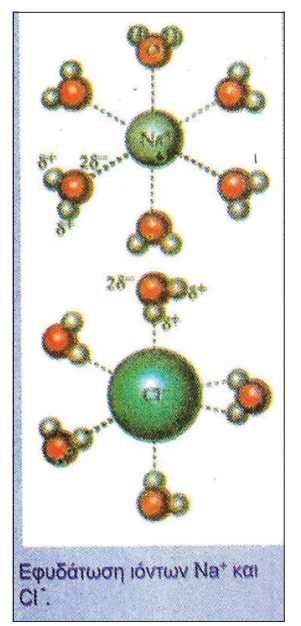

Figure 8: An example of the quasi-three dimensions (3-D) category. Although there is a sense of $3-D$, the relevant place and the orientation of water molecules (which are ligands of the ions $\mathrm{Na}^{+}$and $\mathrm{Cl}^{-}$, when $\mathrm{NaCl}$ is dissolved in water) are not depicted in a realistic 3-D way. The figure was taken from the textbook of Liodakis et al. (2011)

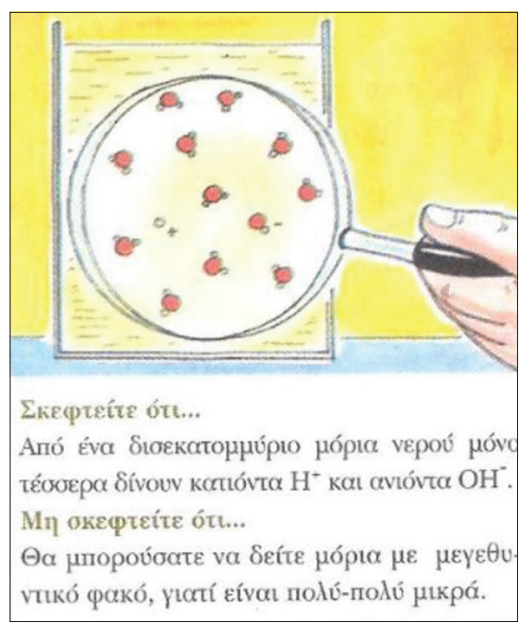

Figure 9: An example of the category in caption > description with clarification. In the caption is written: "Think that..., only four out of one billion molecules of water turn into $\mathrm{H}^{+}$and $\mathrm{OH}^{-}$. Do not think that..., you could see the molecules using a magnifier, since they are too small." The figure was taken from the textbook of Theodoropoulos et al. (2010) 


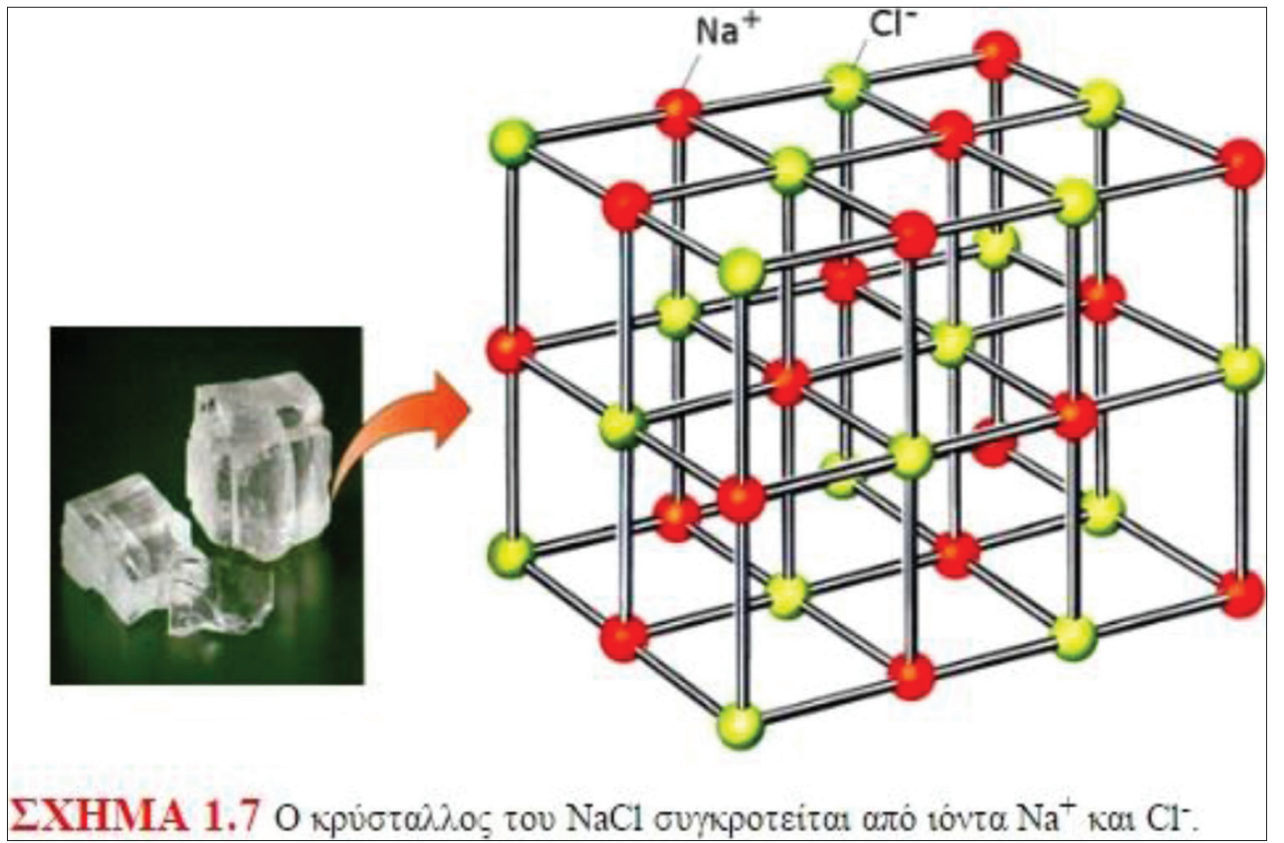

Figure 10: An example of the category submicro-macro-symbolic. Figure 10 depicts lattices of sodium chloride at the macro- and submicro-levels, whereas ions of sodium $\left(\mathrm{Na}^{+}\right)$and chlorine $\left(\mathrm{Cl}^{-}\right)$are also depicted at the symbolic level. The figure was taken from the textbook of Liodakis et al. (2011)

\section{Quantitative Analysis}

The occurrence of taxonomical features is presented in Table 1 for each one of the 3-time periods and in total. As Table 1 shows, the number of VRs in each one of the three periods differs and therefore, the corresponding percentages (\%) were calculated separately on the basis of the corresponding number of VRs for each period. The total percentage was calculated on the basis of the entire sample.

Regarding the type of the VRs, the semi-schematic type constituted the core of the VRs of submicroscopic particles, as their frequencies in total exceeded $60 \%$ of them. This high frequency corresponded to the content of the VRs in this sample; clear communication of unseen phenomena to students requires schematic depiction (Arcavi, 2003). Since the effort of the VRs' designers was probably to ascribe a realistic appearance on the submicroscopic particles and the relevant events, the category of semi-schematic VRs was much more frequent than that of schematic ones. Looking across the periods, the only trends than one can see concern the increase of photographs, probably due to the evolution in the use of the corresponding technology, and the increase of freehand drawings over the decrease of schematic representations.

There were temporal trends in the way of expression. The most interesting was the increased use of models and the decreased use of symbolic representations. In the $1^{\text {st }}$ period (1990-1996), symbolic representations, such as Lewis structures or structural formulae, were quite frequent; whereas in the two other periods they were not observed (there is only one in the $3^{\text {rd }}$ period). Instead, they use of corresponding models (of semi-schematic type in their majority) increased in the $2^{\text {nd }}$ and $3^{\text {rd }}$ periods. It seems that although the discussion for the distinction

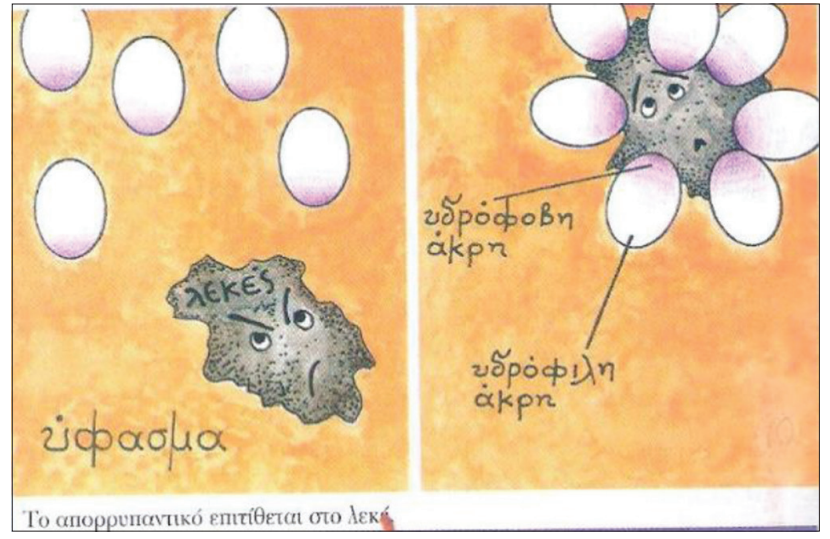

Figure 11: An example of time progressing VR, showing a detergent activity. The figure was taken from the textbook of Theodoropoulos et al. (2010)

between the three levels, macro-, submicro-, symbolic, and the importance of the submicroscopic representations in the chemistry education began in the earlies 90' (Johnstone, 1991, 1993), the implications of the use of submicroscopic representations in the Greek chemistry textbooks were more obvious after the middle of that decade. In any case, the total percentage of models as a way of expression, although quite high as a separate category, actually, was higher due to a large number of models that were also present in the category combination. In this latter category, one can also find symbolic representation, but their purpose was to clarify the entities and the events that were already represented through the use of models. However, although the simultaneous presence of models and symbols in a VR forms a multiple representations that give to students the opportunity to better conceptualize its meaning by providing them with more information 


\begin{tabular}{|c|c|c|c|c|}
\hline Categories & 1990-1996 (82) & 1997-1998 (37) & $2007-2011$ (102) & Total (221) \\
\hline \multicolumn{5}{|l|}{ Type } \\
\hline Photograph & $0.0(0)$ & $8.1(3)$ & $12.7(13)$ & $7.2(16)$ \\
\hline Freehand drawing & $7.3(6)$ & $8.1(3)$ & $14.7(15)$ & $10.9(24)$ \\
\hline Schematic & $19.5(16)$ & $13.5(5)$ & $5.9(6)$ & $12.2(27)$ \\
\hline Semi-schematic & $69.5(57)$ & $51.4(19)$ & $56.9(58)$ & $60.6(134)$ \\
\hline Combination & $3.7(3)$ & $18.9(7)$ & $9.8(10)$ & $9.0(20)$ \\
\hline \multicolumn{5}{|l|}{ Way of expression } \\
\hline Realistic & $0.0(0)$ & $0.0(0)$ & $1.0(1)$ & $0.5(1)$ \\
\hline Analogy/metaphor & $3.7(3)$ & $13.5(5)$ & $2.9(3)$ & $5.0(11)$ \\
\hline Model & $19.5(16)$ & $24.3(9)$ & $44.1(45)$ & $31.7(70)$ \\
\hline Symbolic & $48.8(40)$ & $0.0(0)$ & $1.0(1)$ & $18.6(41)$ \\
\hline Combination & $28.0(23)$ & $62.2(23)$ & $51.0(52)$ & $44.3(98)$ \\
\hline \multicolumn{5}{|l|}{ Sings used } \\
\hline \multicolumn{5}{|l|}{ Entities } \\
\hline Chemical symbols & $72.0(59)$ & $54.1(20)$ & $40.2(41)$ & $54.3(120)$ \\
\hline Balls/cycles & $28.0(23)$ & $73.0(27)$ & $75.5(77)$ & $57.5(127)$ \\
\hline Dots & $22.0(18)$ & $2.7(1)$ & $6.9(7)$ & $11.8(26)$ \\
\hline Macro-object & $6.1(5)$ & $29.7(11)$ & $29.4(30)$ & $20.8(46)$ \\
\hline Miscellaneous & $2.4(2)$ & $10.8(4)$ & $4.9(5)$ & $5.0(11)$ \\
\hline \multicolumn{5}{|l|}{ Motion } \\
\hline Arrows & $6.1(5)$ & $2.7(1)$ & $2.0(2)$ & $3.6(8)$ \\
\hline Orbits & $13.4(11)$ & $0.0(0)$ & $4.9(5)$ & $7.2(16)$ \\
\hline Shadows & $0.0(0)$ & $2.7(1)$ & $5.9(6)$ & $3.2(7)$ \\
\hline \multicolumn{5}{|l|}{ Dimensions } \\
\hline Two dimensional & $86.6(71)$ & $56.8(21)$ & $19.6(20)$ & $50.7(122)$ \\
\hline Three dimensional & $4.9(4)$ & $24.3(9)$ & $37.3(38)$ & $23.1(51)$ \\
\hline Quasi-three dimensional & $6.1(5)$ & $13.5(5)$ & $41.2(42)$ & $23.5(52)$ \\
\hline Combination & $2.4(2)$ & $5.4(2)$ & $0.0(0)$ & $1.8(4)$ \\
\hline \multicolumn{5}{|l|}{ Text included } \\
\hline \multicolumn{5}{|l|}{ Inside } \\
\hline Simple & $50.0(41)$ & $56.8(21)$ & $41.2(42)$ & $47.1(104)$ \\
\hline With clarifications & $0.0(0)$ & $2.7(1)$ & $1.0(1)$ & $0.9(2)$ \\
\hline \multicolumn{5}{|l|}{ Caption } \\
\hline Simple & $76.8(63)$ & $45.9(17)$ & $45.1(46)$ & $57(126)$ \\
\hline With clarifications & $23.2(19)$ & $13.5(5)$ & $31.4(32)$ & $25.3(56)$ \\
\hline None & $0.0(0)$ & $8.1(3)$ & $6.9(7)$ & $4.5(10)$ \\
\hline \multicolumn{5}{|l|}{ Complexity } \\
\hline Simple & $93.9(77)$ & $54.1(20)$ & $66.7(68)$ & $74.7(165)$ \\
\hline Systemic & $4.9(4)$ & $13.5(5)$ & $18.6(19)$ & $12.7(28)$ \\
\hline Macro-submicro-symbol & $1.2(1)$ & $29.7(11)$ & $12.7(13)$ & $11.3(25)$ \\
\hline Time progressing & $0.0(0)$ & $2.7(1)$ & $2.0(2)$ & $1.4(3)$ \\
\hline
\end{tabular}

connecting and complementing one another (Cook, 2006; Tsui and Treagust, 2013), this advantage was moderated due to the increase of the complexity degree. As many researchers suggest (e.g., Cook, 2006; Corradi et al., 2014; Nyachwaya and Gillaspie, 2016; Talanquer, 2011; Treagust et al., 2003), students can benefit from such multiple representations only when they have developed relevant prior knowledge. Otherwise, students spend much of their cognitive power to interpret the (complex for them) representation, a fact that leads to a "cognitive overload" hindering the conceptual understanding of the VR. Thus, any positive or negative effect of this combination of models and symbolic representations can be evaluated only in connection to the curriculum of each grade - probably positive effects increase along with the grade. The existence of one realistic VR in the $3^{\text {rd }}$ period was expected due to the evolution of the technology.

In the above categories and especially in models, symbols, and their combination, particular signs were used for the representation of entities or/and motion. Among them, chemical symbols and balls/cycles (balls or cycles depending on the dimensions of the VR) were used the most, exceeding more than half of the total VRs in each one of these categories. However, they appear opposite trends 
across the three periods, i.e., the use of chemical symbols decreases when that of balls/cycles increases. Apparently, this was expected to a certain degree, since chemical symbols are used in the symbolic way of expression and balls or cycles are used in submicroscopic representations through models (analogous trend compared to that between symbolic and models in the category way of expression). In the representations of motion, the frequencies are generally low with opposite trends between arrows and shadows. The use of shadows for the representation of motion seems to be more contemporary.

A more contemporary trend seems to be also the use of 3-D or quasi-3-D VRs in the chemistry textbooks. Although the majority of the total VRs of the sample are depicted in 2-D, their use is dramatically reduced across the 3 time periods, whereas that of 3-D and quasi-3-D VRs increases. As Wu et al. (2001) suggest, there are many students who would have difficulty in understanding what a 2-D representation would express in a 3-D form. In fact, this is a matter of students' spatial ability, since the correct visualization of such a VR requires the mental transformation of the entire 2-D spatial configuration to the corresponding 3-D (e.g., Tartre, 1990; Voyer et al., 1995). Thus, the increasing use of 3-D VRs seems to facilitate a better understanding of what VRs represent.

As for the text that is included (or not) in our "unit of analysis," the text in a caption was rather more frequent than that inside the VR. In both cases, a simple form of information seems to be more common. Although a number of researchers (e.g., Gkitzia et al., 2011; Nyachwaya and Gillaspie, 2016; Shehab \& BouJaoude, 2017) pointed out the importance of the existence of an appropriate explicit caption, captions with clarifications were limited in the present study, whereas there were only two VRs with clarifications inside the VR in the entire sample. According to Nyachwaya and Gillaspie (2016), the lack of such an explicit caption can cause an additional cognitive load, as students have to focus only on visual information. On the contrary, when information is provided through visual (representation) and verbal (caption) modalities, the cognitive load reduces. This is what Cook (2006) reports as "dual mode effect," according to which, since visual and verbal information are elaborated in students' mind through independent channels having their own capacity, the total load splits, avoiding the cognitive overload in both channels.

The simplicity is also something that characterizes the VRs of submicroscopic particles as for their degree of complexity. Simple VRs are almost the three-quarter of the sample. Among the complex VRs, the systemic ones appear to be the most frequent with an increasing trend across the periods, whereas the category macro-submicro-symbolic is rather present in the two past periods in accordance with those already discussed for multiple representations in the category way of expression.

\section{CONCLUSIONS AND IMPLCIATIONS FOR SCIENCE EDUCATION}

The analysis of the VRs of the sample provided a sufficient variety of categories of illustration characteristics to develop the corresponding taxonomy in an integrated form to some degree. Thus, although such an analysis implemented in another sample of another country could possibly result in some different categories or a different distribution of VRs across the categories, the taxonomy of Figure 1 remains a valuable tool for both, science teachers and VRs designers. The same holds true even for future samples of electronic versions of textbooks or other relevant electronic media, where advances in technologies (e.g., software and graphic technology) can extend this taxonomy. For instance, the category model could be extended including static and dynamic models, since simulations and interactivity are enabled by such advances. Similarly, although multimedia can also give new perspectives in cases of time progressing representations or 3-D representations (e.g., when orientation or rotation are key factors) or even in cases where motion representations are essential, the present taxonomy could be again a basis for the incorporation of any new categories.

For a science teacher, the possession of an integrated view of a VRs illustration characteristics could enable him/her to realize the multiple ways in which the meaning of a VR could be interpreted. For instance, since a teacher is aware of his/her students' prior knowledge related to the content of a VR, (s)he could probably anticipate whether students can conceptualize a multiple representations where submicroscopic and symbolic levels coexist, or a cognitive load could act as a learning obstacle. Thus, (s)he could focus accordingly, giving the necessary instructions. As Talanquer (2011) suggests, this is important, since the overload of students' mind can ultimately have negative consequences even on their motivations for chemistry. Similarly, in cases where an appropriate caption is absent from a VR, a teacher, being aware that students have to conceptualize the meaning of the VR only visually, could help them by giving them verbally more information to reduce cognitive load. Furthermore, the knowledge of taxonomy helps teachers in identifying problems concerning the VRs' dimensions. Although usually (s)he cannot be aware of the spatial abilities of his/her students, (s)he could be more effective in cases of 2-D or quasi-3D representations by emphasizing their transformation to the corresponding 3-D representations. In any case, teachers would be aware of the explanatory power of a VR of submicroscopic particles, and thus, they could act accordingly, supported by appropriate didactic tools any of its weak or tricky points.

All the above are also benefits for a VR designer. However, in this case, there is the privilege of choice. A VR designer can choose any combination of the illustration characteristics of Figure 1 to show what really would like to "see" a student. In this effort, the contemporary trends and possibilities together with the relevant research evidence could also help. 
For instance, the benefits of multiple representation at the macro-, submicro-, and symbolic levels, as they are discussed by the science researchers (e.g., Cook, 2006; Nyachwaya \& Gillaspie, 2016; Treagust et al., 2003), seem to have affected their use over that of the symbolic representations across the three periods, fact that should be taken into account by VRs designers. Similarly, when a designer has the entire "picture" of the choices as for the type of the VR that could be used, the advantages of graphical technology progress or the science evolution and innovations (e.g., STM) can offer more effective solutions. More importantly, VR designers can use the taxonomy as a tool that can serve in maintaining a balance between "information benefits" and "complexity degree." Being aware of the grade where a VR will be used (and probably the students' prior knowledge), they could anticipate whether a simple or a multiple representations would be the most effective. Simple representations, giving emphasis on the submicro-level and avoiding the symbolic one, can better serve low grades, whereas multiple ones could be more effective in high grades (e.g., Cook, 2006; Nyachwaya \& Gillaspie, 2016). On the contrary, independently of grade, designers can be more effective by reducing VRs demands in cognitive load when enrich verbally VRs with sufficient clarifications in the form of a caption or inside them, when they preferably use $3 \mathrm{D}$ representations instead of 2-D ones and when they avoid quasi-3-D representations.

Taking into account the important role of VRs in the effectiveness of textbooks (e.g., Cheng et al., 2015; Kress et al., 2001; Shehab and BouJaoude, 2017) and that textbooks are associated with the curriculum (e.g., Chiappetta and Fillman, 2007; Abd-El-Khalick et al., 2008), the present taxonomy can help in future appropriate design and use of VRs of submicroscopic particles, contributing to a better science curriculum positively affecting the science teaching and learning process.

\section{REFERENCES}

Abd-El-Khalick, F., Waters, M., \& Le, A.P. (2008). Representations of nature of science in high school chemistry textbooks over the past four decades. Journal of Research of Science Teaching, 45(7), 835-855.

Åkerlind, G.S. (2005). Variation and commonality in phenomenographic research methods. Higher Education Research and Development, 24(4), 321-334.

Albertazzi, L. (2013). Handbook of Experimental Phenomenology: Visual Perception of Shape, Space and Appearance. New York: Wiley.

Arcavi, A. (2003). The role of visual representations in the teaching and learning of mathematics. Educational Studies in Mathematics, 52(3), 215-241.

Avramiotis, S., Aggelopoulos, V., Kapelonis, G., Sinigalias, P., Spantidis, D., Trikaliti, A., \& Filos, G. (2007). Chemistry: B' Gymnasium. Athens: OEDB.

Barta, N.S., \& Stille, J.R. (1994). Grasping the concepts of stereochemistry. Journal of Chemical Education, 71(1), 853-855.

Billings, E.M., \& Klanderman, D. (2000). Graphical representations of speed: Obstacles preservice K-8 teachers experience. School Science and Mathematics, 100, 440-450.

Bliss, J., Monk, M., \& Ogborn, J. (1983). Qualitative Data Analysis for Educational Research: A Guide of Systemic Networks. $1^{\text {st }}$ ed. London: Croom Helm.
Boo, H.K. (1998). Students' understandings of chemical bonds and the energetics of chemical reactions. Journal of Research in Science Education, 35(5), 569-581.

Cheng, M.C., Chou, P.I., Wang, Y.T., \& Lin, C.H. (2015). Learning effects of a science textbook designed with adapted cognitive process principles on grade 5 students. International Journal of Science and Mathematics Education, 13(3), 467-488.

Chiappetta, E.L., \& Fillman, D.A. (2007). Analysis of five high school biology textbooks used in the United States for inclusion of the nature of science. International Journal of Science Education, 29(15), 1847-1868.

Cook, M.P. (2006). Visual representations in science education: The influence of prior knowledge and cognitive load theory on instructional design principles. Science Education, 90(6), 1073-1091.

Corradi, D.M.J., Elen, J., Schraepen, B., \& Clarebout, G. (2014). Understanding possibilities and limitations of abstract chemical representations for achieving conceptual understanding. International Journal of Science Education, 36(5), 715-734.

Devetak, I., \& Vogrinc, J. (2013). The criteria of evaluating the quality of the science textbooks. In: Khine, M.S., (Eds.), Critical Analysis of Science Textbooks: Evaluating Instructional Effectiveness. Dordrecht, the Netherlands: Springer. pp. 3-15.

Dimopoulos, K., Koulaidis, V., \& Sklaveniti, S. (2003). Towards an analysis of images in school science textbooks and press articles about science and technology. Research in Science Education, 33(2), 189-216.

Eliam, B., \& Poyas, Y. (2010). External visual representations in science learning: The case of relations among system components. International Journal of Science Education, 32(17), 2335-2366.

Frassari, T., \& Drouka-Liapati, P. (1993). Chemistry: B' Gymnasium. Athens: OEDB.

Georgiadou, T., Kafetzopoulos, K., Provis, N., Spyrelis, N., \& Xiniadis, D. (1998). Chemistry: C'Gymnasium. Athens: OEDB.

Gilbert, J.K. (2008). Visualization: An emergent field of practice and enquiry in science education. In: Gilbert, J.K., Reiner, M., \& Nakhleh, M., (Eds.), Visualization in Science Education. Dordrecht, the Netherlands: Springer. pp. 3-24.

Gilbert, J.K. (2010). The role of visual representations in the learning and teaching of science: An introduction. Asia-Pacific Forum on Science Learning and Teaching, 11(1), 1-19.

Gkitzia, V., Salta, K., \& Tzougraki, C. (2011). Development and application of suitable criteria for the evaluation of chemical representations in school textbooks. Chemistry Education Research and Practice, 12(1), 5-14.

Glynn, S.M., \& Muth, K.D. (1994). Reading and writing to learn science: Achieving scientific literacy. Journal of Research in Science Teaching, 31(9), 1057-1073.

Han, J., \& Roth, W.M. (2006). Chemical inscriptions in Korean textbooks: Semiotics of macro and microworld. Science Education, 90(2), 173-201.

Johnstone, A.H. (1991). Why is science difficult to learn? Things are seldom what they seem. Journal of Computer Assisted Learning, 7, 75-83.

Johnstone, A.H. (1993). The development of chemistry teaching: A changing response to changing demand. Journal of Chemical Education, 70(9), 701-705.

Kozma, R.B., \& Russell, J. (1997). Multimedia and understanding: Expert and novice responses to different representations of chemical phenomena. Journal of Research in Science Teaching, 34(9), 949-968.

Kress, G., Jewitt, C., Ogborn, J., \& Tsatsarelis, C. (2001). Multimodal Teaching and Learning: The Rhetorics of the Science Classroom. London: Bloomsbury.

Kuhn, T. (1970). The Structure of Scientific Revolutions. $2^{\text {nd }}$ ed. Chicago: University of Chicago Press.

Liodakis, S., Gakis, D., Theodoropoulos, D., Theodoropoulos, P., \& Kallis, A. (2011). Chemistry: A' Lyceum. Athens: OEDB.

Marton, F. (1986). Phenomenography a research approach investigating different understandings of reality. Journal of Thought, 21(3), 28-49.

Marton, F., \& Booth, S. (1997). Learning and Awareness. Mahwah, New Jersey: Lawrence Erlbaum Associates.

Mayring, P. (2000). Qualitative content analysis. Forum: Qualitative Social Research, 1(2), 20. Available from: http://www.nbn-resolving.de/ urn: nbn:de:0114-fqs0002204. [Last retrieved on 2019 Jun 07].

Niaz, M., \& Coştu, B. (2009). Presentation of atomic structure in Turkish general chemistry textbooks. Chemistry Education Research and 
Practice, 10(3), 233-240.

Noh, T., \& Scharmann, L.C. (1997). Instructional influence of a molecularlevel pictorial presentation of matter on students' conceptions and problem-solving ability. Journal of Research in Science Teaching, 34(2), 199-217.

Nyachwaya, J.M., \& Gillaspie, M. (2016). Features of representations in general chemistry textbooks: A peek through the lens of the cognitive load theory. Chemistry Education Research and Practice, 17(1), 58-71.

Nyachwaya, J.M., \& Wood, N.B. (2014). Evaluation of chemical representations in physical chemistry textbooks. Chemistry Education Research and Practice, 15(4), 720-728.

Onwu, G.O., \& Randall, E. (2006). Some aspects of students' understanding of a representational model of the particulate nature of matter in chemistry in three different countries. Chemistry Education Research and Practice, 7(4), 226-239.

Papageorgiou, G., Amariotakis, V., \& Spiliotopoulou, V. (2017). Visual representations of microcosm in textbooks of chemistry: Constructing a systemic network for their main conceptual framework. Chemistry Education Research and Practice, 18(4), 559-571.

Patrick, D.M., Carter, G., \& Wiebe, N.E. (2005). Visual representations of DNA replication: Middle grades students' perceptions and interpretations. Journal of Science Education and Technology, 14(3), 353-365.

Pozzer-Ardenghi, L., \& Roth, W.M. (2003). Prevalence, function, and structure of photographs in high school biology textbooks. Journal of Research in Science Teaching, 40(10), 1089-1114.

Rodriguez, M.A., \& Niaz, M. (2004). A reconstruction of structure of the atom and its implications for general physics textbooks: A history and philosophy of science perspective. Journal of Science Education and Technology, 13(3), 409-424.

Roth, W.M., Bowen, G.M., \& McGinn, M.K. (1999). Differences in graphrelated practices between high school biology textbooks and scientific ecology journals. Journal of Research in Science Teaching, 36(9), 9771019.

Sanger, M.J., \& Greenbowe, T.J. (1997). Common student misconceptions in electrochemistry: Galvanic, electrolytic, and concentration cells. Journal of Research in Science Teaching, 34(4), 377-398.

Schnotz, W. (2002). Toward an integrated view of learning from text and visual displays. Educational Psychology Review, 14(1), 101-120.

Shehab, S.S., \& BouJaoude, S. (2017). Analysis of the chemical representations in secondary Lebanese chemistry textbooks. International Journal of Science and Mathematics Education, 15(5), 797-816.

Slough, S.W., McTigue, E.M., Kim, S., \& Jennings, S.K. (2010). Science textbooks' use of graphical representation: A descriptive analysis of four sixth grade science texts. Reading Psychology, 31(3), 301-325.

Souza, A.F.D., \& Porto, A. (2012). Chemistry and chemical education through text and image: Analysis of twentieth century textbooks used in Brazilian context. Science and Education, 21(5), 705-727.

Spiliotopoulou-Papantoniou, V., Karantanou, A., Panagiotakopoulos, C., \& Koustourakis, G. (2009). Visual representations of internet in Greek school textbooks and students' experiences. Education and Information Technologies, 14(3), 205-227.

Stinner, A. (1992). Science textbooks and science teaching: From logic to evidence. Science Education, 76(1), 1-16.

Talanquer, V. (2011). Macro, submicro, and symbolic: The many faces of the chemistry "triplet". International Journal of Science Education, 33(2), 179-195.

Tartre, L.A. (1990). Spatial orientation skill and mathematical problem solving. Journal for Research in Mathematics Education, 21(3), 216-229.

Theodoropoulos, P., Papatheofanous, P., \& Sideri, F. (2010). Chemistry: C' Gymnasium. Athens: OEDB.

Treagust, D., Chittleborough, G., \& Mamiala, T. (2003). The role of submicroscopic and symbolic representations in chemical explanations. International Journal of Science Education, 25(11), 1353-1368.

Tsui, C.Y., \& Treagust, D.F. (2013). Introduction to multiple representations: Their importance in biology and biological education. In: Treagust, D.F., \& Tsui, C.Y., (Eds.), Multiple Representations in Biological Education. Dordrecht, the Netherlands: Springer. pp. 3-18.

Voyer, D., Voyer, S., \& Bryden., M.P. (1995). Magnitude of sex differences in spatial abilities: A meta-analysis and consideration of critical variables. Psychological Bulletin, 117(2), 250-270.

Wu, H.K., \& Shah, P. (2004). Exploring visuospatial thinking in chemistry learning. Science Education, 88(3). 465-492.

Wu, H.K., Krajcik, J.S., \& Soloway, E. (2001). Promoting understanding of chemical representations: Students' use of a visualization tool in the classroom. Journal of Research in Science Teaching, 38(7), 821-842.

Yore, L.D., Craig, M.T., \& Maguire, T.O. (1998). Index of science reading awareness: An interactive constructive model, test verification, and grades 4-8 results. Journal of Research in Science Teaching, 35(1), 27-51. 


\section{APPENDIX}

\section{Appendix: The chemistry textbooks that were analyzed}

\section{Periods of the Textbooks}

\begin{tabular}{ll}
\hline $1^{\text {st }}$ period (1990-1996) & \\
$8^{\text {th }}$ Grade: & Frassari, T. \& Drouka-Liapati, P. (1993). Chemistry: B' Gymnasium. Athens: OEDB. \\
$9^{\text {th }}$ Grade: & Frassari, T., \& Drouka-Liapati, P. (1996). Chemistry: C'Gymnasium. Athens: OEDB. \\
$10^{\text {th }}$ Grade: & Sakellaridis, O.P. (1990). Chemistry: A'Lyceum. Athens: Idrima Evgenidou. \\
$2^{\text {nd }}$ period (1997-1998) & \\
$8^{\text {th }}$ Grade: & Georgiadou, T., Kafetzopoulos, K., Provis, N., Spyrelis, N., \& Xiniadis. D. (1997). \\
& Chemistry: B' Gymnasium. Athens: OEDB. \\
$9^{\text {th }}$ Grade: & Georgiadou, T., Kafetzopoulos, K., Provis, N., Spyrelis, N., \& Xiniadis. D. (1998). \\
& Chemistry: C' Gymnasium. Athens: OEDB. \\
$10^{\text {h }}$ Grade: & Mavropoulos, M., \& Kapetanou, E. (1998). Chemistry: A'Lyceum. Athens: OEDB. \\
$3^{\text {rd }}$ period (2007-2011) & Avramiotis, S., Aggelopoulos, V., Kapelonis, G., Sinigalias, P., Spantidis, D., Trikaliti, \\
$8^{\text {th }}$ Grade: & A., \& Filos, G. (2007). Chemistry: B' Gymnasium. Athens: OEDB. \\
& Theodoropoulos, P., Papatheofanous, P., \& Sideri, F. (2010). Chemistry: C'Gymnasium. \\
$9^{\text {th }}$ Grade: & Athens: OEDB. \\
& Liodakis, S., Gakis, D., Theodoropoulos, D., Theodoropoulos, P., \& Kallis, A. (2011). \\
& Chemistry: A'Lyceum. Athens: OEDB. \\
\hline
\end{tabular}

